Check for updates

Cite this: RSC Adv., 2018, 8, 42068

Received 28th November 2018 Accepted 8th December 2018

DOI: $10.1039 / c 8 \mathrm{ra09804b}$

rsc.li/rsc-advances

\section{Phenalenyl based neutral radical as a novel electrochromic material modulating visible to short-wave infrared light $\uparrow$}

\author{
Dejan Stekovic (D) *ab and Mikhail E. Itkis (iD *abc
}

Applications for energy saving smart windows require materials which can switch from transmissive to black states in both the visible and short-wave IR range. We introduce an electrochromic phenalenyl based neutral radical small molecule and design devices capable of modulating light in both of these ranges.

\section{Introduction}

Electrochromic materials are highly desired due to their large number of applications such as wearable electronics, E-papers, sunglasses, energy saving windows and more. ${ }^{1}$ These materials, which possess the ability to change colors upon the application of an electrical potential, have been composed of metal oxides, ${ }^{2}$ small molecules ${ }^{3}$ and polymers ${ }^{4}$ among others. ${ }^{5} \mathrm{~A}$ special subset of these materials is able to switch between transmissive and black states showing wide spectral range electrochromism. ${ }^{6}$ There are a number of strategies to accomplish this, most of which include the use of multiple electrochromic materials. For example, several groups have used polymer mixtures to achieve transmissive to black modulations. ${ }^{7}$

One of the most commonly proposed uses of electrochromic materials that can switch from a transmissive to black state is in smart windows. ${ }^{8}$ Over $50 \%$ of total energy use in a building is estimated to be attributed to cooling, heating and lighting, ${ }^{9}$ and a significant energy saving can be achieved by incorporating electrochromic materials into windows in order to control the solar energy entering the building. While various groups have shown the ability to modulate visible light for natural controlled lighting and energy saving purposes, approximately $50 \%$ of the energy emitted by the sun that reaches the earth is from infrared light ranging from 700 to $2500 \mathrm{~nm}$ ( short-wave infrared (SWIR)). ${ }^{9}$ Thus, in order to build effective smart windows capable of reducing energy use in buildings this IR irradiation cannot be ignored and must be modulated along with visible light. Here we demonstrate the use of a phenalenyl based neutral radical as

\footnotetext{
${ }^{a}$ Department of Chemistry, University of California, Riverside, California 92521, USA. E-mail:dstek001@ucr.edu

${ }^{b}$ Center for Nanoscale Science and Engineering, University of California, Riverside, California 92521, USA

${ }^{c}$ Department of Chemical and Environmental Engineering, University of California, Riverside, California 92521, USA. E-mail: mitkis@engr.ucr.edu

$\uparrow$ Electronic supplementary information (ESI) available: Experimental, spectra of device components and picture of CNT-device. See DOI: 10.1039/c8ra09804b
}

a new small molecule based electrochromic material capable of switching from a transmissive to black state in the visible to short-wave IR range.

Phenalenyl based neutral radical conductors, pioneered by R. C. Haddon, ${ }^{10}$ have been studied extensively. One of the most interesting compounds is bis(9 $\mathrm{N}$-butylamino-1-oxophenalene) boron $\left([\mathrm{PLY}(\mathrm{O}, \mathrm{NBu})]_{2} \mathrm{~B}\right)$ which in solid crystalline state demonstrated a hysteretic phase transition in vicinity of room temperature accompanied by a unique bistability observed simultaneously in electrical, magnetic and optical properties. ${ }^{11}$ As a small spiroconjugated molecule, $[\mathrm{PLY}(\mathrm{O}, \mathrm{NBu})]_{2} \mathrm{~B}$ can be reversibly reduced $(-0.733 \mathrm{~V} v \text { s. SCE })^{12}$ in solution state from its cationic state to a neutral radical state (Fig. 1a). Similar to the commonly used electrochromic viologens, ${ }^{13}$ this reduction is accompanied by a change in color. However, unlike viologens, which go from transmissive to single color states, $[\mathrm{PLY}(\mathrm{O}, \mathrm{NBu})]_{2} \mathrm{~B}$ goes from a transmissive red-orange state to a black opaque material. This can be seen in the solid state where $[\mathrm{PLY}(\mathrm{O}, \mathrm{NBu})]_{2} \mathrm{~B}$ can exist as the red colored cationic salt or the black neutral radical crystals (Fig. 1b and c), as well as in solution where the cationic state is orange and transmissive, and the neutral radical state is black and opaque (Fig. 1d and e). While $[\mathrm{PLY}(\mathrm{O}, \mathrm{NBu})]_{2} \mathrm{~B}$ 's solid state properties have been extensively studied, its use as an electrochromic material has yet to be

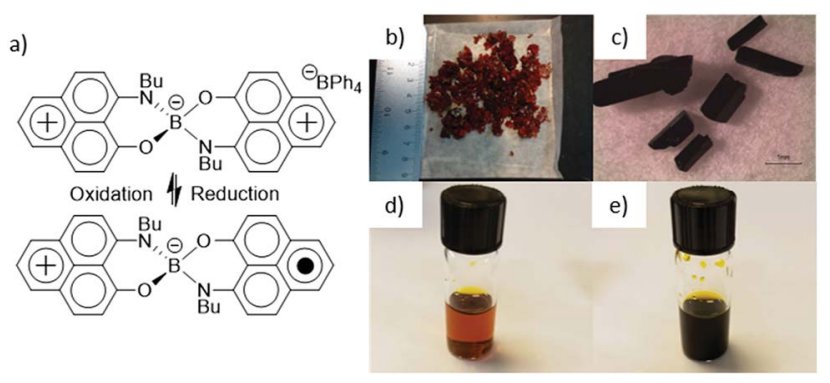

Fig. 1 (a) Cationic and neutral radical structure of $[P L Y(O, N B u)]_{2} B$ along with their ( $b$ and $c$ ) solid state and ( $d$ and $e$ ) in solution pictures. Scale bar in (c) is $1 \mathrm{~mm}$. 
addressed, even though the small molecule possesses the rare transmissive to black transition.

\section{Results and discussion}

To test the electrochromic properties of $[\mathrm{PLY}(\mathrm{O}, \mathrm{NBu})]_{2} \mathrm{~B}$ an electrochromic cell is built. A configuration similar to that of viologen based devices is used, where an electrochromic material is dissolved in solution with an oxidant (or reductant). At applied potentials the electrochromic material is reduced (or oxidized) causing a color change to occur. ${ }^{\mathbf{1 4}}$ When the potential

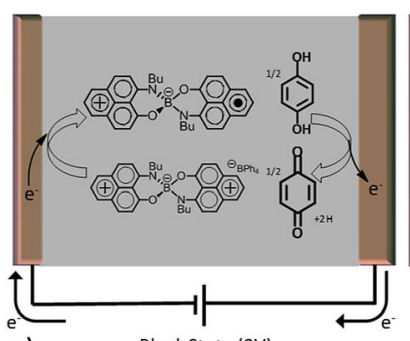

a)

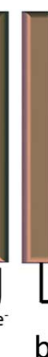

b)

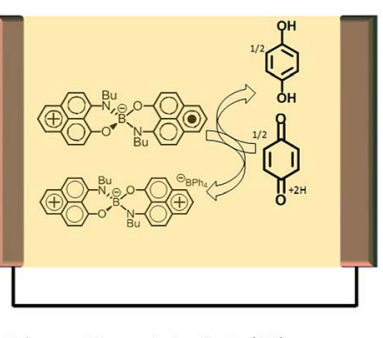

Transmissive State (OV)
Fig. 2 Electrochemistry of electrochromic device operations. (a) At an applied potential, $[P L Y(O, N B u)] 2 B^{+}$is reduced to the neutral radical $[\mathrm{PLY}(\mathrm{O}, \mathrm{NBu})] 2 \mathrm{~B}$ (1 electron reduction) while hydroquinone is oxidized to 1,4-benzoquinone (2 electron oxidation) resulting in a black state. (b) When no potential is applied (O V) $[P L Y(O, N B u)] 2 B$ and 1,4-benzoquinone diffuse and $[\mathrm{PLY}(\mathrm{O}, \mathrm{NBu})] 2 \mathrm{~B}$ is oxidized to $[\mathrm{PLY}(\mathrm{O}, \mathrm{NBu})] 2 \mathrm{~B}^{+}$ while 1,4-benzoquinone is reduced to hydroquinone (transmissive state). is removed the molecules diffuse into one another and a redox reaction occurs causing the regeneration of the original optical state. Here, a solution of $[\mathrm{PLY}(\mathrm{O}, \mathrm{NBu})]_{2} \mathrm{~B}^{+} \mathrm{BPh}_{4}{ }^{-}$(tetraphenylborate) and hydroquinone in propylene carbonate is placed between two indium tin oxide (ITO) covered glass substrates to form an electrochromic cell as schematically presented in Fig. 2. Upon application of a potential between opposing ITO electrodes, transmissive cationic $[\mathrm{PLY}(\mathrm{O}, \mathrm{NBu})]_{2} \mathrm{~B}^{+}$is reduced to its black neutral radical form and hydroquinone is oxidized to 1,4benzoquinone. The use of a second component which can be reversibly oxidized, in this case hydroquinone, has previously been shown to improve the electrochromic properties of small molecules in electrochromic devices. ${ }^{\mathbf{1 4}}$

The reduction of $[\mathrm{PLY}(\mathrm{O}, \mathrm{NBu})]_{2} \mathrm{~B}^{+}$to the neutral radical $[\mathrm{PLY}(\mathrm{O}, \mathrm{NBu})]_{2} \mathrm{~B}$ is visually observed through a change of the cell from a yellow transmissive to a black state as shown in Fig. 3a. Thus, the color of the device is determined by the electrochemical redox reactions between the electrochromic material and either the electrode (to reduce) or the oxidant (to oxidize).

Fig. $3 \mathrm{~b}$ shows the visible and partial near-IR range transmittance spectra of the device in its bleached and colored state. The bleached state shows a relatively high transparency of $\sim 65 \%$ at wavelengths above $500 \mathrm{~nm}$ switching to a transmittance of $10-30 \%$ in the black state. Some loss of transmittance in the bleached state is partially due to the contribution of two ITO covered glass substrates (Fig. S1 $\dagger$ ) and can be reduced by further device optimization. The cycling stability of the electrochromic cell was tested at $575 \mathrm{~nm}$ by
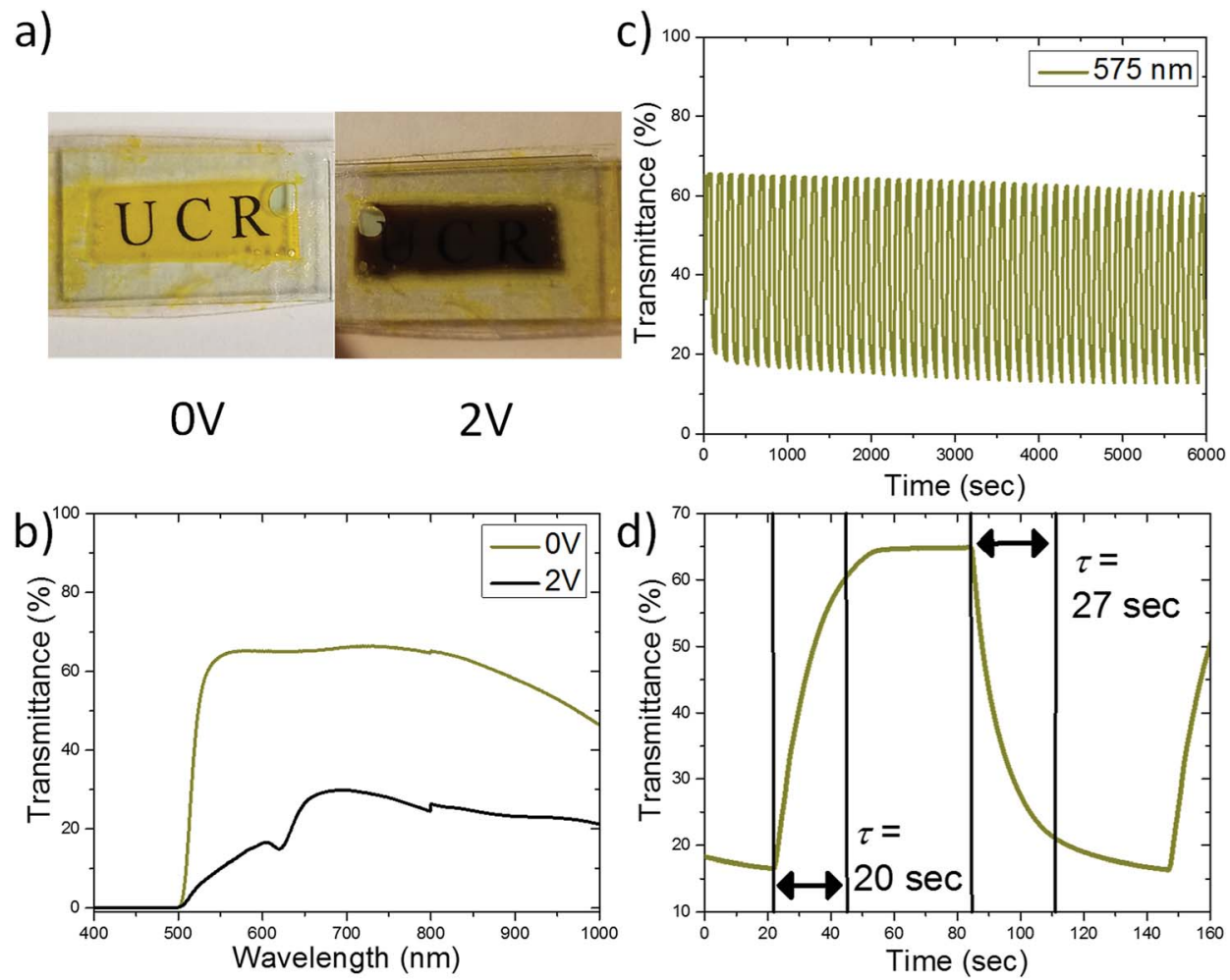

Fig. 3 Electrochromic properties of $[\mathrm{PLY}(\mathrm{O}, \mathrm{NBu})]_{2} \mathrm{~B}$ in an ITO-glass sandwich structure. (a) Pictures of devices in clear and black state. (b) Accompanying transmittance spectra. (c) Cycling response at $575 \mathrm{~nm}$ and (d) corresponding response time. 
switching applied potentials between $+2.0 \mathrm{~V}$ (60 seconds) and $0 \mathrm{~V}$ (60 seconds). After several activation cycles at $575 \mathrm{~nm}$ the full amplitude of transmission $(T)$ modulation between the transmissive state $(T \approx 65 \%)$ and black state $(T \approx 18 \%)$ has been achieved with the amplitude of modulation $(\Delta T \approx 47 \%)$ maintained at least for $6000 \mathrm{~s}$ (50 cycles) (Fig. 3c).

The response time $(\tau)$, defined as the time it takes for the device to reach $90 \%$ of its saturation signal, was evaluated at the level of 20-30 seconds as shown in Fig. 3d at $575 \mathrm{~nm}$. The response dynamics are controlled by the time required for the reduction of $[\mathrm{PLY}(\mathrm{O}, \mathrm{NBu})]_{2} \mathrm{~B}$ (for darkening) and the time required for the reduced $[\mathrm{PLY}(\mathrm{O}, \mathrm{NBu})]_{2} \mathrm{~B}$ and oxidized hydroquinone (benzoquinone) to diffuse and meet each other in order to exchange charge (for bleaching) (Fig. 2). The response time of the device is sufficient for smart window applications ${ }^{8}$ and can be further improved by optimizing the device design and geometry as shown in our previous reports and discussed in the literature. ${ }^{15}$

While modulating visible light is important, for energy saving smart windows infrared light from 700-2500 nm $(\sim$ SWIR) must also be considered as it is responsible for approximately half of the energy output from the sun that reaches the earth. ${ }^{9}$ Thus, an ideal smart window would modulate both visible and short wave infrared light. Testing short wave IR light modulation using the above device is prevented by the strong absorption of conducting ITO above a wavelength of $1200 \mathrm{~nm}$ (Fig. S1c and $\mathrm{d} \dagger$ ). In order to expand the spectral range of electrochromic devices to the SWIR range ITO must be replaced. Thus, in a new set of devices the ITO conducting layers on both electrodes were substituted with films of metallic single-walled carbon nanotubes (MT-SWNTs) as discussed in recent studies. ${ }^{15 a, e, 16}$ The metallic type of SWNTs was selected because it has less interfering spectral features and lower absorption in both visible and the SWIR spectral ranges than semiconducting SWNTs, and it provides a very efficient transparent conductive layer at very low thicknesses $(30 \mathrm{~nm})$ as shown in Fig. S2. $\dagger$ Fig. S3† shows a picture of the device in its transmissive $(0 \mathrm{~V})$ and colored $(2 \mathrm{~V})$ state, and it can be seen that it shows the transmissive to black transition in the visible range similar to the ITO based device. Fig. 4a specifically shows device operation in SWIR range. MT-SWNT thin films are very transmissive in visible and SWIR spectral range, so the device with MT-SWNT transparent electrodes can be efficient in both spectral ranges. In the IR area of interest, 1000-2500 $\mathrm{nm}$, the average transmittance in the bleached and colored state is $64.9 \%$ and $24.0 \%$ respectively demonstrating a high degree of modulation $(\Delta T \approx 41 \%)$. Fig. $4 \mathrm{~b}$ shows the cycling of the device over 6000 seconds ( 60 seconds at $2 \mathrm{~V}, 60$ seconds at $0 \mathrm{~V}$ ) and not much degradation is observed showing that the electrochromic properties are reversible. The response time is on the order of 10 seconds (Fig. 4d), which is shorter than in case of the ITO electrodes in agreement with our recent report. ${ }^{15 a}$ A significant amount of absorptions in both the bleached and colored states in the range from $1000-2500 \mathrm{~nm}$ is due to propylene carbonate, a solvent used in the cell (Fig. $\mathrm{S} 2 \dagger$ ). Fig. 4c presents the transmittance spectra of the device with the propylene carbonate

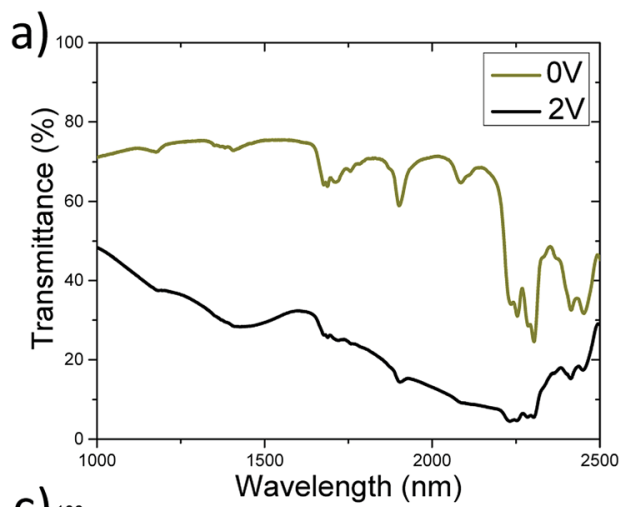

b)
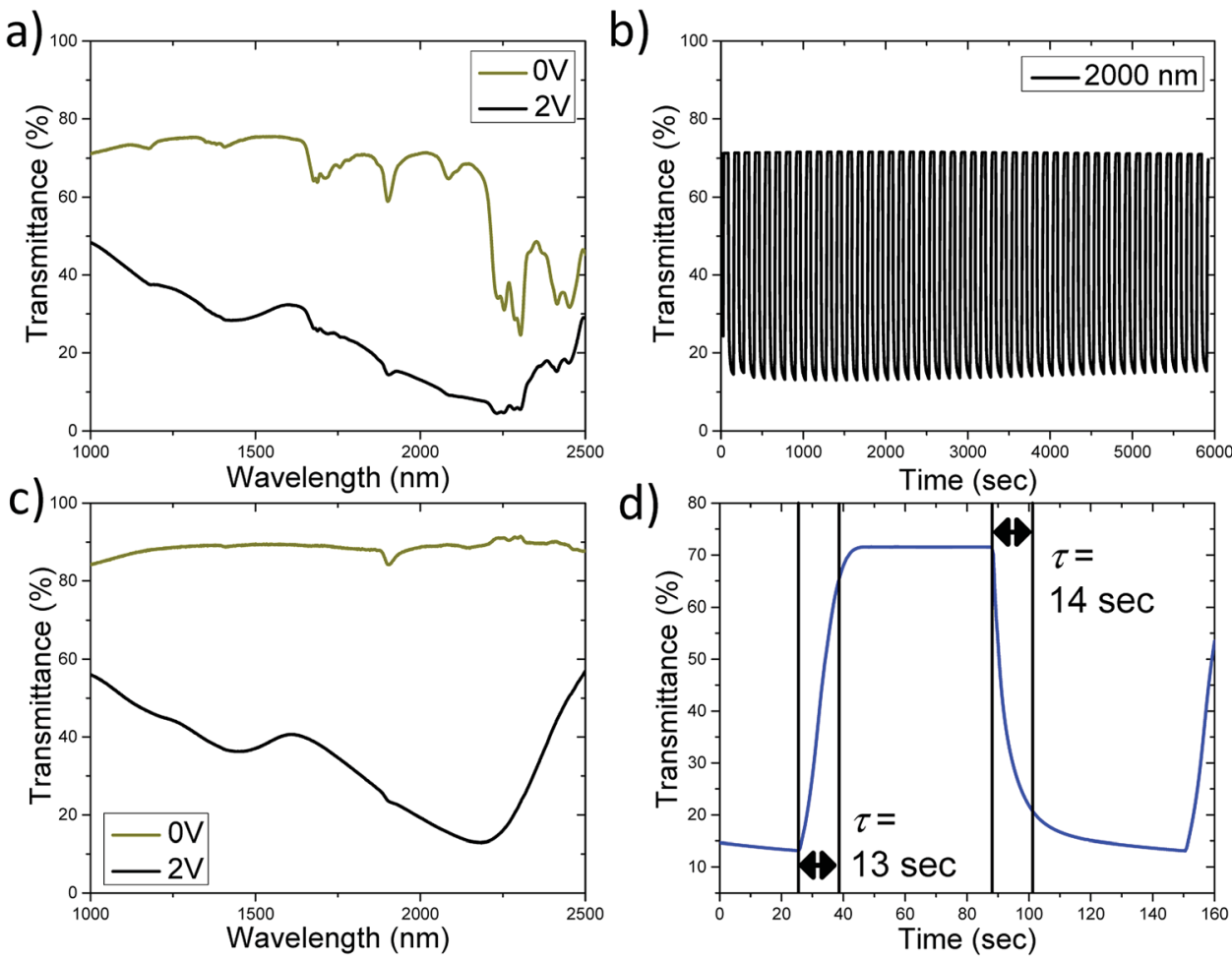

Fig. 4 Electrochromic properties of $[P L Y(O, N B u)]_{2} B$ in an MT-SWNT on glass sandwich structure. (a) Transmittance spectra including the propylene carbonate solvent (c) and with solvent subtracted out from 1000-2500 nm (b) cycling response of device at $2000 \mathrm{~nm}$ and (d) corresponding response time. 
subtracted out. It shows a significant increase of the transparency of the bleached state if the losses due to solvent are reduced along with an increased amplitude of the transmittance modulation $(\Delta T)$ up to $70 \%$ at $2200 \mathrm{~nm}$. Thus, using thinner cells with less solvent in the optical path can improve the performance of the electrochromic cell.

Also, in the present design (both ITO and MT-SWNT based), our device contains a thick layer of $[\mathrm{PLY}(\mathrm{O}, \mathrm{NBu})]_{2} \mathrm{~B}$ solution (pathlength $\sim 0.3 \mathrm{~mm}$ ), however reduction only occurs at the conducting electrode (ITO or SWNT) to solvent interface, and it is likely that much of the $[\mathrm{PLY}(\mathrm{O}, \mathrm{NBu})]_{2} \mathrm{~B}$ is not reduced and thus does not contribute to the dark state while retarding the clear state. Thus, reducing the thickness of the solvent containing electrochromic layer could increase the transparency of the transmissive state and the efficiency of use of $[\mathrm{PLY}(\mathrm{O}, \mathrm{NBu})]_{2} \mathrm{~B}$ material without compromising the performance.

Recently, there has been an interest in flexible electrochromic devices. Incorporation of small molecules into gel electrolytes, which allows for the fabrication of flexible devices based on viologens has been demonstrated. ${ }^{\mathbf{1 4}}$ Thus, future studies could explore the inclusion of $[\mathrm{PLY}(\mathrm{O}, \mathrm{NBu})]_{2} \mathrm{~B}$ in such a flexible device for transmissive to black wearable electronic applications. The ultimate solution could be achieved via the development of a solid state flexible version of the neutral radical based electrochromic device through adsorption of the small molecules onto a conductive substrate as has been shown in the literature, mainly in the field of dye sensitized solar cells, but also shown in electrochromic applications. ${ }^{17}$

\section{Conclusions}

In conclusion, we presented a phenalenyl based small molecule, $[\mathrm{PLY}(\mathrm{O}, \mathrm{NBu})]_{2} \mathrm{~B}$, as a novel electrochromic material, potentially interesting for smart windows development. $[\mathrm{PLY}(\mathrm{O}, \mathrm{NBu})]_{2} \mathrm{~B}$ is able to modulate both visible and SWIR light which combined are responsible for most of the energy emitted from the sun that reaches the earth. Future studies could include optimization of the electrochromic cell design including a solid state option of the device and exploring other biphenalenyl based small molecules for expanding the spectral range and improving electrochromic performances of this new class of electrochromic materials.

\section{Conflicts of interest}

There are no conflicts to declare.

\section{Notes and references}

1 (a) P. H. Yang, P. Sun and W. J. Mai, Mater. Today, 2016, 19, 394-402; (b) C. Y. Hsu, J. Zhang, T. Sato, S. Moriyama and M. Higuchi, ACS Appl. Mater. Interfaces, 2015, 7, 1826618272; (c) S. Beaupre, A. C. Breton, J. Dumas and M. Leclerc, Chem. Mater., 2009, 21, 1504-1513.

2 (a) H. D. Zheng, J. Z. Ou, M. S. Strano, R. B. Kaner, A. Mitchell and K. Kalantar-Zadeh, Adv. Funct. Mater., 2011, 21, 2175-
2196; (b) D. T. Gillaspie, R. C. Tenent and A. C. Dillon, J. Mater. Chem., 2010, 20, 9585-9592; (c) K. K. Chiang and J. J. Wu, ACS Appl. Mater. Interfaces, 2013, 5, 6502-6507.

3 (a) M. Stolar, J. Borau-Garcia, M. Toonen and T. Baumgartner, J. Am. Chem. Soc., 2015, 137, 3366-3371; (b) Y. M. Zhang, X. J. Wang, W. R. Zhang, W. Li, X. F. Fang, B. Yang, M. J. Li and S. X. A. Zhang, Light: Sci. Appl., 2015, 4, e249.

4 (a) H. J. Yen and G. S. Liou, Polym. Chem., 2012, 3, 255-264; (b) P. M. Beaujuge and J. R. Reynolds, Chem. Rev., 2010, 110, 268-320; (c) G. Gunbas and L. Toppare, Chem. Commun., 2012, 48, 1083-1101.

5 (a) Z. Q. Ji, S. K. Doorn and M. Sykora, ACS Nano, 2015, 9, 4043-4049; (b) S. Q. Liu, D. G. Kurth, H. Mohwald and D. Volkmer, Adv. Mater., 2002, 14, 225-228.

6 H. J. Yen, K. Y. Lin and G. S. Liou, J. Mater. Chem., 2011, 21, 6230-6237.

7 (a) H. Shin, Y. Kim, T. Bhuvana, J. Lee, X. Yang, C. Park and E. Kim, ACS Appl. Mater. Interfaces, 2012, 4, 185-191; (b) Q. Zhang, C. Y. Tsai, T. Abidin, J. C. Jiang, W. R. Shie, L. J. Li and D. J. Liaw, Polym. Chem., 2018, 9, 619-626; (c) H. S. Liu, B. C. Pan, D. C. Huang, Y. R. Kung, C. M. Leu and G. S. Liou, NPG Asia Mater., 2017, 9, e388; (d) P. M. Beaujuge, S. Ellinger and J. R. Reynolds, Nat. Mater., 2008, 7, 795-799; (e) W. T. Neo, C. M. Cho, Z. G. Shi, S. J. Chua and J. W. Xu, J. Mater. Chem. C, 2016, 4, 28-32; (f) S. Abraham, S. Mangalath, D. Sasikumar and J. Joseph, Chem. Mater., 2017, 29, 9877-9881; $(g)$ L. R. Savagian, A. M. Österholm, D. E. Shen, D. T. Christiansen, C. M. Kuepfert and J. R. Reynolds, Adv. Opt. Mater., 2018, 6, 1800594.

8 (a) C. G. Granqvist, Thin Solid Films, 2014, 564, 1-38; (b) R. Baetens, B. P. Jelle and A. Gustavsen, Sol. Energy Mater. Sol. Cells, 2010, 94, 87-105; (c) C. Nakamura, K. Manabe, M. Tenjimbayashi, Y. Tokura, K. H. Kyung and S. Shiratori, ACS Appl. Mater. Interfaces, 2018, 10, 22731-22738.

9 H. Khandelwal, A. P. H. J. Schenning and M. G. Debije, $A d v$. Energy Mater., 2017, 7, 1602209.

10 R. C. Haddon, Nature, 1975, 256, 394-396.

11 (a) S. K. Pal, P. Bag, A. Sarkar, X. L. Chi, M. E. Itkis, F. S. Tham, B. Donnadieu and R. C. Haddon, J. Am. Chem. Soc., 2010, 132, 17258-17264; (b) M. E. Itkis, X. Chi, A. W. Cordes and R. C. Haddon, Science, 2002, 296, 14431445; (c) M. Fumanal, J. J. Novoa and J. Ribas-Arino, Chem.-Eur. J., 2017, 23, 7772-7784.

12 X. Chi, M. E. Itkis, K. Kirschbaum, A. A. Pinkerton, R. T. Oakley, A. W. Cordes and R. C. Haddon, J. Am. Chem. Soc., 2001, 123, 4041-4048.

13 Y. Alesanco, A. Vinuales, G. Cabanero, J. Rodriguez and R. Tena-Zaera, ACS Appl. Mater. Interfaces, 2016, 8, 2961929627.

14 (a) H. C. Moon, C. H. Kim, T. P. Lodge and C. D. Frisbie, ACS Appl. Mater. Interfaces, 2016, 8, 6252-6260; (b) J. Palenzuela, A. Vinuales, I. Odriozola, G. Cabanero, H. J. Grande and V. Ruiz, ACS Appl. Mater. Interfaces, 2014, 6, 14562-14567.

15 (a) D. Stekovic, B. Arkook, G. Li, W. Li, E. Bekyarova and M. E. Itkis, Adv. Mater. Interfaces, 2018, 1800861; (b) 
D. E. Shen, A. M. Osterholm and J. R. Reynolds, J. Mater. Chem. C, 2015, 3, 9715-9725; (c) J. Weissbecker, A. Loas, S. M. Gorun and D. Schlettwein, Electrochim. Acta, 2015, 157, 232-244; (d) J. H. Ko, S. Yeo, J. H. Park, J. Choi, C. Noh and S. U. Son, Chem. Commun., 2012, 48, 38843886; (e) M. L. Moser, G. Li, M. Chen, E. Bekyarova, M. E. Itkis and R. C. Haddon, Nano Lett., 2016, 19, 53865393.

16 (a) J. Y. Wan, Y. Xu, B. Ozdernir, L. Xu, A. B. Sushkov, Z. Yang, B. Yang, D. Drew, V. Barone and L. B. Hu, ACS Nano, 2017, 11, 788-796; (b) S. V. Vasilyeva, E. Unur, R. M. Walczak, E. P. Donoghue, A. G. Rinzler and
J. R. Reynolds, ACS Appl. Mater. Interfaces, 2009, 1, 22882297.

17 (a) S. Shankar, M. Lahav and M. E. van der Boom, J. Am. Chem. Soc., 2015, 137, 4050-4053; (b) L. Zhang and J. M. Cole, ACS Appl. Mater. Interfaces, 2015, 7, 3427-3455; (c) L. A. Zotti, T. Kirchner, J. C. Cuevas, F. Pauly, T. Huhn, E. Scheer and A. Erbe, Small, 2010, 6, 1529-1535; (d) U. Bach, D. Lupo, P. Comte, J. E. Moser, F. Weissortel, J. Salbeck, H. Spreitzer and M. Gratzel, Nature, 1998, 395, 583-585; (e) D. Weng, Y. C. Shi, J. M. Zheng and C. Y. Xu, Org. Electron., 2016, 34, 139-145. 